\title{
Gross and Histological Alteration in the Placenta in Gestational Diabetes - A Comparative Study
}

\author{
Gopalakrishnan Asha, ${ }^{1}$ Sukumaran Thottiyil Tintu, ${ }^{1}$ Mathew Joselet Asha, ${ }^{1}$ \\ 'Department of Anatomy, Amrita School of Medicine, Kochi Kerala, India
}

Disclose and conflicts of interest: none to be declared by all authors

\section{ABSTRACT}

Introduction: the placenta is a fetomaternal organ that separates the maternal and fetal circulation. It is a vital organ for fetal development and is a mirror of the maternal and fetal status. The essential elements of the placenta are the chorionic villi from the fetal side and the decidual plate from the maternal side. Fetal blood circulates through capillaries in the villi. The villi are surrounded by maternal blood. The maternal and fetal bloods are separated by a very thin placental membrane. The fully formed placenta is $\sim 6$ inches in diameter and weighs $\sim 500 \mathrm{~g}$. Its metabolic functions are complex and it undergoes changes continuously throughout gestation in weight, structure, shape and function in order to support prenatal life. Materials and Methods: a total of 50 gestational diabetic mellitus (GDM) and 50 normal placentae were utilized for the present study. Placental shape was visualized, classified, and the weight, volume, thickness and circumference of the placenta were measured. Tissue for histological examination was taken from central and peripheral zones of the placenta. Microscopic findings, number of villi, diameter of the villi, number of capillaries in each villi, and the diameter of capillaries were noted. Results: macroscopically, there is increase in weight, volume, and circumference of GDM placentae than in the control group. The present study also showed an increase in number and diameter of villi and in the number of capillaries in each villus in the gestational diabetic mellitus placentae other than control group and it is statistically significant.

Conclusion: the present study supports that there is very a strong relationship between placenta morphometry and diabetes mellitus.

Keywords: Clinical anatomy; Embryology and cell biology; Macroscopic human anatomy; Placenta; Villi; Gestational diabetes mellitus; Capillaries.

\section{Introduction}

The term placenta comes from the Greek word "plakoenta", which means "flat slab like", in reference to its round flat appearance in humans. The placenta is the primary site of nutrient and gas exchange between the mother and fetus. It has three main functions, namely: metabolism, transport of nutrients and gases and endocrine secretion of numerous hormones. These comprehensive activities are executed for maintaining pregnancy and promoting normal fetal development.

The placenta consists of the chorionic plate on the fetal side and of the basal plate on the maternal side. At term, the placenta is disc-like and has fetal and maternal surfaces and a peripheral margin. The fetal surface is smooth, covered by amnion, with the umbilical cord attached close to its center. The maternal surface is rough, irregular, and 15 to 30 polygonal areas known as cotyledons are discernable. Fissures limit the cotyledons and a placental septum separates it. At term, it has a diameter of rv $20 \mathrm{~cm}$ and weighs rv 500 g. ${ }^{1}$

Histologically, the placenta is constituted by villi with fetal blood and intervillous spaces with maternal blood. The primary villus consists of cytotrophoblast covered by syn-cytiotrophoblast; in the secondary villus there is a central core of primary mesoderm; and in the tertiary villous the mesoderm is invaginated by fetal blood vessels. The terminal villi constitute the functional unit of the placenta, therefore the human placenta is of a discoid, deciduate, hemochorial and villous type. ${ }^{1}$

Diabetes mellitus (DM) is nowa major health concern in our society according to the Centers for Disease Control and Prevention, Atlanta, GA, USA. It is a common metabolic disor-der and, during pregnancy, it produces complications both in mother and offspring. Diabetes mellitus in pregnant women may be categorized into pregestational diabetes or clinical DM and gestational diabetes mellitus (GDM). According to the Centers for Disease Control and Prevention, The incidence of diagnosed diabetes increases in pregnancy. Any type of DM during pregnancy produces a variety of placental abnormalities. Studies suggest that the prevalence of DM among women of childbearing age is increasing due to a more sedentary life style, dietary habits and adolescent obesity. Diabetic placenta has attracted much interest, primarily because it is thought that placental damage may be partially responsible for the high incidence of fetal malformations in pregnancies.

Pregnancy can induce a diabetogenic state by virtue of various physiological changes which cause 
insulin resis-tance. This is referred to as GDM. In GDM, morphological changes occur in the placenta in relation to its weight, surface area, thickness, and number of cotyledons. Histological changes include increase in the number of capillaries in the villi, chorangiosis, increase in the diameter of the villi and changes in the intervillous volume.

The objective of the present study is to compare morphological and histomorphometric changes in placentae from mothers with GDM and to compare the parameters with the placentae of normal mothers.

\section{Materials and Methods}

A total number of 100 placentae were observed, of which 50 were of GDM mothers, and 50 normal placentas constituted the control group. They were collected from the labor theater of the Amrita Institute of Medical Science and Research Centre and relevant medical history of the mother and baby were noted from the data available in the hospital records. The present study was performed in the Department of Anatomy, Amrita School of Medicine, Kochi. The placentae were washed under running tap water to remove the blood clots and were blotted with absorbable cloth to dry them.

\section{Macroscopic Examination}

The following parameters were considered. 1) shape by obser-vation, 2) weight of the placenta measured up to the nearest gram with a digital weighing machine, 3 ) volume of the placenta taken by displacement method, 4) thickness in the center measured by inserting a fine needle through and through and measured up to the nearest millimeter, 5) thick-ness in the periphery measured by inserting a fine needle through and through and measuring up to the nearest milli meter, 6) circumference was calculated by finding the radius using a measuring tape and applying the $2 \prod \mathrm{r}$ formula.

\section{Microscopic Examination}

All of the placentas were immersed in $10 \%$ formalin for 72 hours. For each placenta whole thickness tissue were abtained from the centre and periphery.

The tissues were taken and were processed by routine paraffin embedding, sections were made with the help of a microtome. The slides were prepared, stained with Hematoxy-lin and Eosin (H\&E) and mounted in Dibutylphthalate Polysty-rene Xylene (DPX). The prepared slides were examined under light microscope and photographs were taken. Microscopic measurements were performed with an eyepiece micrometer (Erma Inc. Ocular Micrometer, Tokyo, Japan). The eyepiece micrometer was calibrated using a stage micrometer (Erma Inc. Objective Micrometer, Tokyo, Japan). Parameters noted for central and peripheral zones of each placenta were: 1. number of villi, 2. number of capillaries in the villi, 3. average diameter of the villi, 4 . average diameter of the villous capillaries.

\section{Statistical Analysis}

The data obtained was analyzed using IBM SPSS Statistics for Windows, Version 20 (IBM Corp., Armonk, NY, USA). The statistical significance between the control and diabetic group was evaluated by using the Student unpaired t- test. Data was presented as mean \pm standard deviation [SD]. A $p$-value $<0.05$ was considered statistically significant.

\section{Results}

A total number of 100 placentae were utilized in the present study, of which 50 were GDM placenta and 50 constituted the control group.

\section{Macroscopic Findings}

Results were tabulated in Table 1 and Table 2.

\section{Microscopic Findings}

Figure 1, Figure 2, Table 3 and Table 4.

\section{Discussion}

\section{A. Morphology}

1. Shape of the placenta: Fig. 3. In the present study, 30 oval (60\%) and 20 circular (40\%) placentae were observed in the diabetic group. In the control group, 10 oval $(20 \%)$ and 40 circular $(80 \%)$ placentae were Weight of the placenta: In the present study, the mean placental weight of the diabetic group was $572.92 \mathrm{~g}$ and that of the control group was $467.2 \mathrm{~g}$. In 2017, Bhanu et al studied 48 control and 48 GDM placentae and stated that in the diabetic group the mean placen-tal weight was $537.27 \mathrm{~g}$ and in the control group it was $412.08 \mathrm{~g} .7$ In the present study, the range was similar. Studies done by Saini et al in 2016 included 40 control and 40 diabetic placentae from a North Indian Popula-tion and found out that the mean weight of the diabetic group was $426.25 \mathrm{~g}$, and in the control group it was 397.50 g.4 Increased placental weight was the placental abnormality most consistently studied and reported. this study of 30 diabetic and 30 control placentae, $60 \%$ of the GDM placentae were oval-shaped and, in the control group, $55 \%$ of the placentae were ovalshaped. $^{3}$

\begin{tabular}{l|c|c|c|c}
\hline \multicolumn{1}{c|}{ Table 1. Placental shape } \\
\hline $\begin{array}{c}\text { Placental } \\
\text { Shape }\end{array}$ & $\begin{array}{c}\text { GDM } \\
(\boldsymbol{n}=\mathbf{5 0})\end{array}$ & Percentage & $\begin{array}{c}\text { Control } \\
(\boldsymbol{n}=\mathbf{5 0})\end{array}$ & Percentage \\
\hline Oval & 30 & $60 \%$ & 10 & $20 \%$ \\
\hline Circular & 20 & $40 \%$ & 40 & $80 \%$ \\
\hline
\end{tabular}

Abbreviation: GDM, gestational diabetes mellitus. 
Table 2. Placental morphometry

\begin{tabular}{l|c|c|c}
\hline \multicolumn{1}{c|}{ Parameters } & $\begin{array}{c}\text { Diabetic group } \\
(\text { Mean } \pm \text { SD) }\end{array}$ & $\begin{array}{c}\text { Control group } \\
\text { (Mean } \pm \text { SD) }\end{array}$ & p-value \\
\hline $\begin{array}{l}\text { Placental weight } \\
\text { (grams) }\end{array}$ & $572.92 \pm 163.41$ & $467.2 \pm 46.68$ & 0.003 \\
\hline $\begin{array}{l}\text { Placental } \\
\text { volume } \\
\text { (cm3) }\end{array}$ & $4491 \pm 27.88$ & $373.2 \pm 53.36$ & 0.0087 \\
\hline $\begin{array}{l}\text { Placental } \\
\text { circumference } \\
\text { (cm) }\end{array}$ & $52.5 \pm 14.15$ & $44.64 \pm 6.60$ & 0.0152 \\
\hline $\begin{array}{l}\text { Placental } \\
\text { thickness }(\mathrm{cm})\end{array}$ & $2.06 \pm 0.68$ & $1.12 \pm 0.27$ & $0.0001^{*}$ \\
\hline
\end{tabular}

Abbreviation: SD, standard deviation.

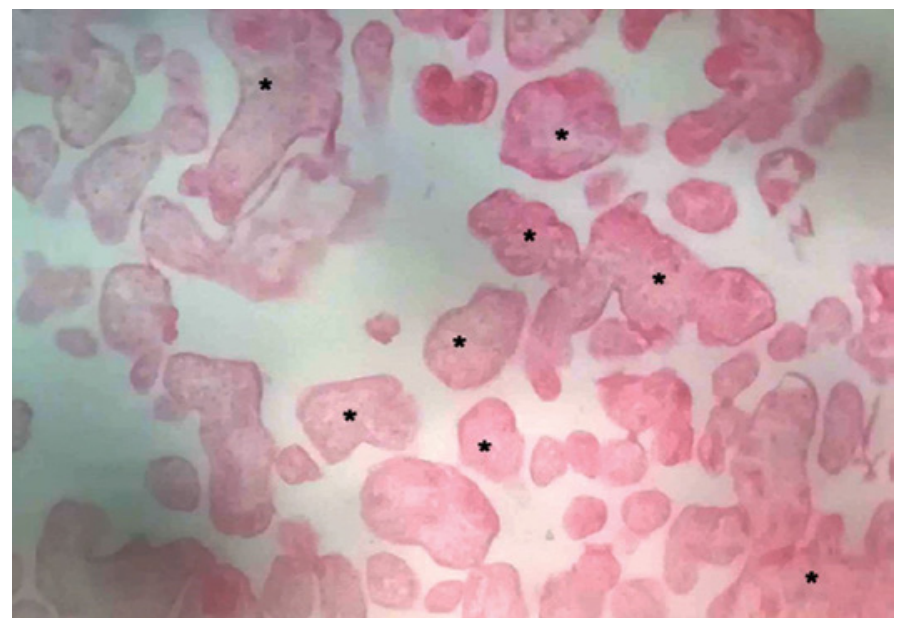

Figure 1. Photograph of control placenta showing normal sized villi (black *) and capillaries (H\&E; 10X).

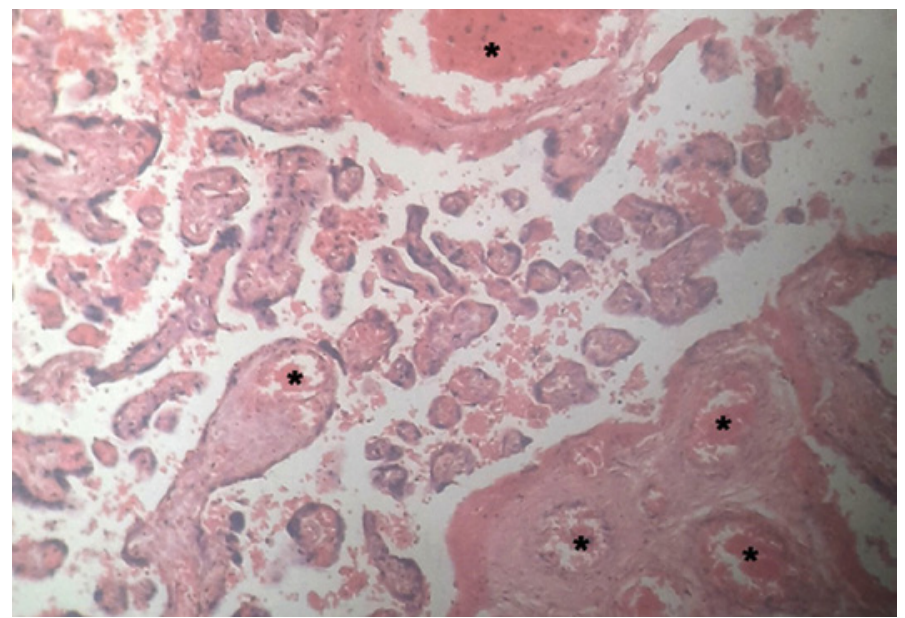

Figure 2. Photograph of GDM placenta with large calibre capillaries (black*) and large villi (H\&E; 10X).

2. Thickness of the placenta: In the present study, the control group showed a mean central thickness of $1.12 \mathrm{~cm}$ and, in the periphery, $0.86 \mathrm{~cm}$. The GDM group showed a mean central thickness of $2.06 \mathrm{~cm}$ and, in the periphery, $1.06 \mathrm{~cm}$. Saini et al, in 2015, studied 40 control and 40 diabetic placentae and observed that the mean central thickness in the control group was
$1.96 \mathrm{~cm}$ and, in the GDM group, it was $2.12 \mathrm{~cm} .{ }^{4}$ These findings showed similarity to our study. Elsennavy, in 2016, studied 30 control and 30 GDM placentae and found out that the control group showed a mean central thickness of $2.43 \mathrm{~cm}$, and the GDM group showed a central thickness of $2.67 \mathrm{~cm}^{3}$. Neither of the authors considered the peripheral thickness.

3. Volume of the placenta: Pala HG et $a l^{5}$ in 2015 , studied 39 GDM and 42 normal placentae and observed that the placental volume in GDM was 411.59 $\mathrm{cm}^{3}$ and $343 \mathrm{~cm}^{3}$ in the control group. ${ }^{5}$ Saha et al, in 2013, studied 60 normal and 70 diabetic placentae and observed that the mean placental volume in GDM was $487.65 \mathrm{~cm}^{3}$, andin the control group it was $419.11 \mathrm{~cm}^{3}{ }^{6}$ In the present study, the mean placental volume of the GDM group was $449 \mathrm{~cm}^{3}$, and in the control group it was $373.2 \mathrm{~cm}^{3}$. All these studies indicate that in GDM the size of the placenta is significantly greater.

4. Weight of the placenta: In the present study, the mean placental weight of the diabetic group was 572.92 $\mathrm{g}$ and that of the control group was $467.2 \mathrm{~g}$. In 2017, Bhanu et al studied 48 control and 48 GDM placentae and stated that in the diabetic group the mean placental weight was $537.27 \mathrm{~g}$ and in the control group it was 412.08 g.7 In the present study, the range was similar. Studies done by Saini et al in 2016 included 40 control and 40 diabetic placentae from a North Indian Population and found out that the mean weight of the diabetic group was $426.25 \mathrm{~g}$, and in the control group it was 397.50 g.4 Increased placental weight was the placental abnormality most consistently studied and reported.

5. Circumference of the placenta: In the present study, we found that the GDM group showed a mean circum-ference of $52.5 \mathrm{~cm}$, which is greater than the control group, which was $\sim 44.64 \mathrm{~cm}$. Saha et al, in 2014, studied 60 control and 70 diabetic placentae in Kolkata and observed that the mean circumference in the control group was $48.35 \mathrm{~cm}$, and in the GDM group it was $52.32 \mathrm{~cm} .6$ These results are similar to those of our study.

B. Microscopic studies: In 2011, Tewari et al obtained specimens from the Government Medical Colleges Luck-now and Kanpur and observed that in diabetic placenta there is a profusion of villi.8 Gheorman et al, in 2011, also studied 19 diabetic placentae and observed numerous cell populations in the villous stroma.9 Similar findings were observed in the present study. Bhanu et al, in 2016, studied diabetic placentae and observed that the mean number of terminal villi is increased in GDM placentae, with values of 9.01 for the GDM group and of 5.44 for the control group. ${ }^{7}$ We observed the mean number of villi in the center of the placenta to be 5.44 in the GDM group, and of 2.64 in the control group. In the periphery of the placenta, the mean number of villi for the GDM group was 5.92. This is substantially higher than the control group, in which the average was 2.96 . 
Table 3. Histometrical findings of placental villi

\begin{tabular}{l|c|c|c|c}
\hline \multicolumn{1}{c|}{ Parameter } & Diabetic group (Mean \pm SD) & Control group (Mean \pm SD) & p-value & Significant \\
\hline Number of villi (center) & $5.44 \pm 2.31$ & $2.64 \pm 1.07$ & $<0.0001$ & yes \\
\hline Number of villi (periphery) & $5.92 \pm 2.1$ & $2.96 \pm 0.97$ & $<0.0001$ & yes \\
\hline Villi diameter (central) & $0.12 \pm 0.026$ & $0.08 \pm 0.007$ & $<0.0001$ & yes \\
\hline Villi diameter (periphery) & $0.11 \pm 0.029$ & $0.08 \pm 0.009$ & $<0.0001$ & yes \\
\hline
\end{tabular}

Abbreviation: SD, standard deviation.

Table 4. Histometrical findings of placental capillaries in the gestational diabetes mellitus and in the control group

\begin{tabular}{|c|c|c|c|c|}
\hline Parameter & $\begin{array}{c}\text { Diabetic }(n=50) \\
(\text { Mean } \pm \text { SD })\end{array}$ & $\begin{array}{c}\text { Control }(n=50) \\
(\text { Mean } \pm \text { SD) }\end{array}$ & p-value & Significant \\
\hline Number of capillaries (center) & $4.38 \pm 0.75$ & $2.48 \pm 0.50$ & $<0.0001$ & yes \\
\hline Number of capillaries (periphery) & $3.88 \pm 0.66$ & $2.7 \pm 0.45$ & $<0.0001$ & yes \\
\hline Blood vessel diameter (center) & $0.047 \pm 0.014$ & $0.023 \pm 0.007$ & $<0.0001$ & yes \\
\hline Blood vessel diameter (periphery) & $0.04 \pm 0.014$ & $0.015 \pm 0.005$ & $<0.0001$ & yes \\
\hline
\end{tabular}

Abbreviation: SD, standard deviation.

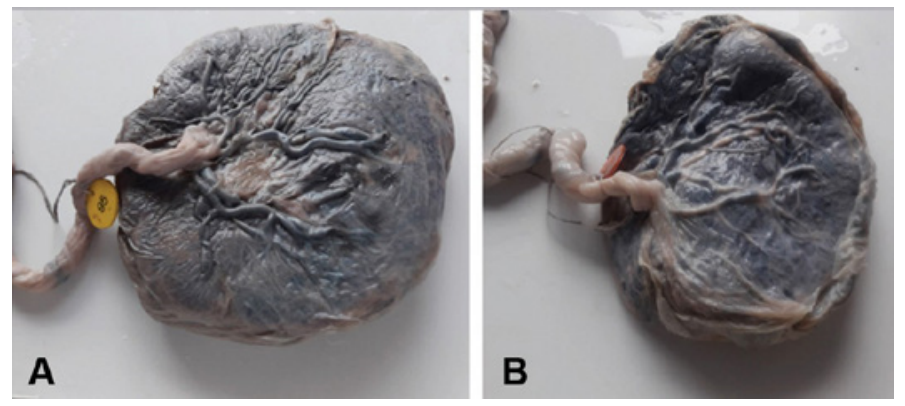

Figure 3. Shapes of diabetic placenta. (A: Round, B: Oval).

Verma et al, in 2010, in New Delhi, studied 25 placentae, of which 20 placentae were GDM and 5 were control, and they observed that dispersal vascular pattern of the chorionic blood vessels of the placenta were more frequent in GDM.10 Gheor-man et al, in 2011, studied 19 diabetic placentae and observed an increased number of villous capillaries, the so-called chor-angiosis. ${ }^{9}$ In our study, in the GDM group, we observed that the mean number of capillaries in each villus in the center of the placenta was 4.38 , and in the control group it was 2.48. In the periphery of the placenta, the mean number of capillaries in each villus was 3.88 in the GDM group, and in the control group it was 2.7. Elsennavy et al, in 2016, in Egypt, studied 30 control and 30 diabetic placentae and observed that the peripheral villi showed more frequent blood capillaries than the central villi, but in the present study the central villi showed a higher number of capillaries. $^{3}$

Jirkovská et al, in 2012, studied 17 diabetic and 14 control placentae and observed that the diameter of the capillaries increased in GDM placentae. ${ }^{11}$ In the present study, we observed that the diameter of capillaries of the GDM placen-tae was increased, and the average mean diameter of the capillaries was $0.047 \mathrm{~mm}$, whereas in the control group it was 0.023 $\mathrm{mm}$. The diameter of capillaries in the periphery was observed to be 0.04 in the GDM group, whereas in the control group the diameter of capillaries was $0.01 \mathrm{~mm}$.

Higgins et al, in 2011, studied 18 women with GDM and 10 controls and observed that capillary volume was increased in GDM pregnancies. ${ }^{12}$ Bhanu et al, in 2016 studied 96 placentae, of which 48 were GDM and 48 were controls, in the General Hospital Nellore Andhra Pradesh, and they observed that the mean diameter of the villi of GDM placentae was $0.08 \mathrm{~mm}$, and in the control group it was $0.07 \mathrm{~mm} .^{7}$ In our study, we observed that in GDM placentae, the diameter of the villi was $0.12 \mathrm{~mm}$ and, in the control group, it was 0.08 $\mathrm{mm}$. The measurements in the present study exceeded those of this comparative study. We also studied the villi diameter of the periphery and observed that in the GDM group the mean diameter was $0.11 \mathrm{~mm}$, and in the control group it was $0.8 \mathrm{~mm}$.

Treesh et al, in 2015, in Libya, studied 7 control and 13 GDM placentae and observed that there is an increased number of villous capillaries and dilated blood vessels in diabetic placentae,${ }^{13}$ but did not distinguish central and peripheral zones.

\section{Conclusion}

In the present studymacroscopic andmicroscopic changes in 50 GDM placentae and 50 normal placentae were compared. We found a significant increase in weight, volume, circumference, and thickness in GDMplacentae. Microscopically, the number of large villi, number of capillaries in the villi, diameter of the villi, and diameter of the capillaries were significantly higher than those of the control group. The present study supports the view that there is a very strong cause and effect relationship between the placenta and DM. Clinically, the adverse effects of diabetes on the outcome of pregnancy is well-established, but we have attempted to see the gross morphological and microscopical impacts on the placenta. 


\section{References}

1. Persaud M, Before WAB. Essentials of Embryology and Birth Defects. $6^{\text {th }}$ ed. Elsevier Science; 2003.

2. Tiwari V, Manik P, Pankaj AK, Pandey A, Rani A. Study of shape of placenta and its relation to placental weight in normal and diabetic pregnancies. Int J Multidisciplinary Res Development 2015;2:666-669. 3. Elsennawy TM. Effect of gestational diabetes on gross morphology, histology and histochemistry of human placenta. Endocrinol Metab Syndr 2016;5:1-3.

4. Saini P, Jai P, Anjali J, Gyan C. Effect of gestational diabetes mellitus on gross morphology of placenta: A comparative study. Int J Anat Res 2015;3:889-89.

5. Pala HG, Artunc-Ulkumen B, Koyuncu FM, Bulbul-Baytur Y. Threedimensional ultrasonographic placental volume in gestational diabetes mellitus. J Matern Fetal Neonatal Med 2016;29(04): 610-614. 6. Saha S, Biswas S, Mitra D, Adhikari A, Saha C. Histologic and morphometric study of human placenta in gestational diabetes mellitus. Ital J Anat Embryol 2014;119(01):1-9.

7. Bhanu S, Sankar D, Kiran S, Devi S. Morphological and micrometrical changes of the placental terminal villi in normal and pregnancies complicated with gestational diabetes mellitus. J Evid Based Med. Healthc 2016 (94943).

8. Tewari V, Tewari A, Bhardwaj N. Histological and histochemical changes in placenta of diabetic pregnant females and its comparision with normal placenta. Asian Pac J Trop Dis 2011;1:1-4.

9. Gheorman L, Pleşea IE, Gheorman V. Histopathological considerations of placenta in pregnancy with diabetes. Rom J Morphol Embryol 2012;53(02):329-336.

10. Verma R, Mishra S, Kaul JM. Cellular changes in the placenta in pregnancies complicated with diabetes. Int J Morphol 2010; 28:259-264.

11. Jirkovská M, Kučera T, Kaláb J, et al. The branching pattern of villous capillaries and structural changes of placental terminal villi in type 1 diabetes mellitus. Placenta 2012;33(05): 343-351.

12. Higgins M, Felle P, Mooney EE, Bannigan J, McAuliffe FM. Stereology of the placenta in type 1 and type 2 diabetes. Placenta 2011; 32(08):564-569.

13. Treesh SA, Khair NS. Histological changes of the human placenta in pregnancies complicated with diabetes. J Cytol Histol 2015;6:1.
Received: March 29, 2019

Accepted: September 4, 2019
Corresponding author

Mathew Joselet Asha

Email: ashajmathew@gmail.com 